\title{
Assessment of the Burning Rate of Liquid Fuels in Confined \\ and \\ Compartments Approach \\ Mechanically-Ventilated \\ using a Well-Stirred Reactor
}

\author{
Tarek Beji \\ Ghent University - UGent, Dept. Flow, Heat and Combustion Mechanics, Sint- \\ Pietersnieuwstraat 41, B-9000 Ghent, Belgium
}

\author{
Bart Merci \\ Tel: +32 (0)92649846 \\ Fax: +32 (0)9 2643575 \\ Email: Tarek.Beji@UGent.be \\ Email2: tarekbj@gmail.com
}

Ghent University - UGent, Dept. Flow, Heat and Combustion Mechanics, SintPietersnieuwstraat 41, B-9000 Ghent, Belgium

\begin{abstract}
The objective of this work is to provide a 'support tool' to assess the burning rate of a pool fire in a well-confined and mechanically-ventilated room using a single-zone model based on conservation equations for mass, energy and oxygen concentration. Such configurations are particularly relevant for nuclear facilities where compartments are generally sealed from one another and connected through a ventilation network. The burning rates are substantially affected by the dynamic interaction between the fuel mass loss rate and the rate of air supplied by mechanical ventilation. The fuel mass loss rate is controlled by (i) the amount of oxygen available in the room (i.e. vitiation oxygen effect) and (ii) the thermal enhancement via radiative feedback from the hot gas to the fuel surface. The steady-state burning rate is determined by the 'interplay' and balance between the limiting effect of oxygen vitiation and the enhancing effect of radiative feedback. An extensive sensitivity study over a wide range of fuel areas and mechanical ventilation rates shows that a maximum burning rate may be obtained. For the studied HTP (Hydrogenated Tetra-Propylene) pool fires, the maximum burning rate is up to 1.75 times the burning rate in open air conditions.
\end{abstract}




\section{Keywords}

Nuclear facilities; mechanical ventilation; burning rate; heat release rate; wellstirred reactor model

\section{Acknowledgements}

The research activities as described in this paper were funded by Bel V through a post-doctoral research grant (contract number A12/TT/0617). 


\title{
Assessment of the Burning Rate of Liquid Fuels in \\ Confined \\ and \\ Compartments Approach \\ Mechanically-Ventilated \\ using a Well-Stirred Reactor
}

\begin{abstract}
The objective of this work is to provide a 'support tool' to assess the burning rate of a pool fire in a well-confined and mechanically-ventilated room using a single-zone model based on conservation equations for mass, energy and oxygen concentration. Such configurations are particularly relevant for nuclear facilities where compartments are generally sealed from one another and connected through a ventilation network. The burning rates are substantially affected by the dynamic interaction between the fuel mass loss rate and the rate of air supplied by mechanical ventilation. The fuel mass loss rate is controlled by (i) the amount of oxygen available in the room (i.e. vitiation oxygen effect) and (ii) the thermal enhancement via radiative feedback from the hot gas to the fuel surface. The steady-state burning rate is determined by the 'interplay' and balance between the limiting effect of oxygen vitiation and the enhancing effect of radiative feedback. An extensive sensitivity study over a wide range of fuel areas and mechanical ventilation rates shows that a maximum burning rate may be obtained. For the studied HTP (Hydrogenated Tetra-Propylene) pool fires, the maximum burning rate is up to 1.75 times the burning rate in open air conditions.
\end{abstract}

\section{Keywords}

Nuclear facilities; mechanical ventilation; burning rate; heat release rate; wellstirred reactor model

\author{
Nomenclature \\ A $\quad$ area $\left(\mathrm{m}^{2}\right)$ \\ $c_{p} \quad$ specific heat $(\mathrm{kJ} / \mathrm{kg} . \mathrm{K})$ \\ $F \quad$ configuration factor (-) \\ $H \quad$ height (m) \\ $h_{c} \quad$ convective heat transfer coefficient $\left(\mathrm{kW} / \mathrm{m}^{2} . \mathrm{K}\right)$ \\ $h_{k} \quad$ conduction heat transfer coefficient $(\mathrm{kW} / \mathrm{m} . \mathrm{K})$ \\ $k \quad$ conductivity $(\mathrm{kW} / \mathrm{m} . \mathrm{K})$ \\ $L_{v} \quad$ heat of vaporization of the fuel $(\mathrm{kJ} / \mathrm{kg})$
}




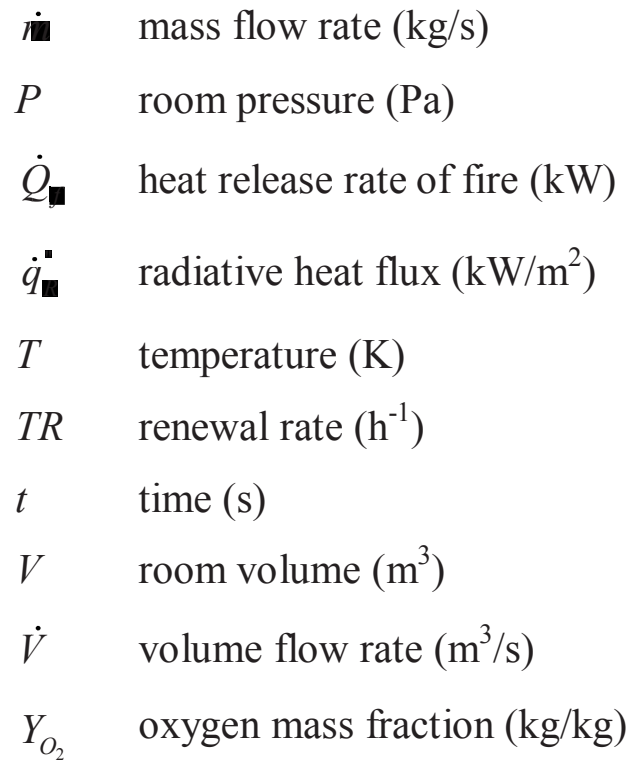


$w \quad$ walls (+ceiling and floor)

$0 \quad$ initial condition

$\infty \quad$ limiting rate

\section{Introduction}

In the design of fire safety systems it is essential to provide reliable estimates of the burning and heat release rates for the prediction of the fire-induced thermal environment and the subsequent tenability conditions and structural response. The burning behaviour of several types of fuels has been extensively investigated theoretically, numerically and experimentally in both open atmosphere and confined conditions. A large body of the literature has been devoted to a comprehensive characterization of naturally-ventilated enclosure fires (e.g. [111]), whereas fewer studies have focused on mechanically-ventilated room fires (e.g. [12-17]). The latter configuration is particularly relevant for the nuclear industry where compartments are generally sealed from one another and connected through a ventilation network. It is highly valuable, however, to discuss first some findings from naturally-ventilated fires, as they will be addressed in the modeling proposed hereafter for mechanically-ventilated fires.

The burning rate in an enclosure depends mainly on:

- the available fuel area,

- the pyrolysis and combustion properties of the fuel (e.g. heat of pyrolysis, vaporization temperature and heat of combustion),

- the oxygen supply (i.e. ventilation conditions), and

- the heat flux received from the flames and hot gases at the fuel surface.

In a naturally-ventilated enclosure fire, after an initial fuel-controlled stage, the fire might reach ventilation-controlled conditions which are determined by the size of the vents (e.g. doorways). It has been established that the inflow of air is proportional to the ventilation factor expressed as $A_{o p} H_{o p}^{1 / 2}$, where $A_{o p}$ is the area of the opening and $H_{o p}^{1 / 2}$ is its height. The burning rate is then proportional to $A_{o p} H_{o p}^{1 / 2}$ in ventilation controlled conditions. This finding has been confirmed in a number of experimental studies [8-9, 18]. The burning rates in enclosure fires can be several times higher than in free-burn conditions due to the thermal feedback to 
the fuel source. This has been confirmed by several studies, such as [1-2] . In [1], the radiative enhancement of burning rate was up to six times the 'open' burning rate for ethanol pool fires in a reduced-scale compartment. These experimental findings were reasonably predicted by a model including the thermal feedback process and the authors proposed a diagrammatic sketch showing the burning rate enhancement (see Fig. 1). In [2], methanol fires were studied in reduced-scale cubic compartments with a single rectangular opening, centrally located in one wall. The fuel tray, $0.15 \mathrm{~m}$ by $0.15 \mathrm{~m}$, was located in the centre of the compartment floor. The internal dimensions of the cube sides were $0.15 \mathrm{~m}, 0.25$ $\mathrm{m}, 0.4 \mathrm{~m}, 0.5 \mathrm{~m}, 0.6 \mathrm{~m}$ and $0.7 \mathrm{~m}$, respectively. Similarly to [1], the results show that the burning rates increase substantially (e.g., up to 7 times the free-burn value in the $0.6 \mathrm{~m}$ cube) with increasing ventilation factor. When a critical value of $A_{o p} H_{o p}^{1 / 2}$ is reached, the burning rate drops very sharply to values approaching asymptotically the open atmosphere value. This clear sudden drop was confirmed through many repetitions of runs. This phenomenon is referred to in [2] as a "critical phenomenon".

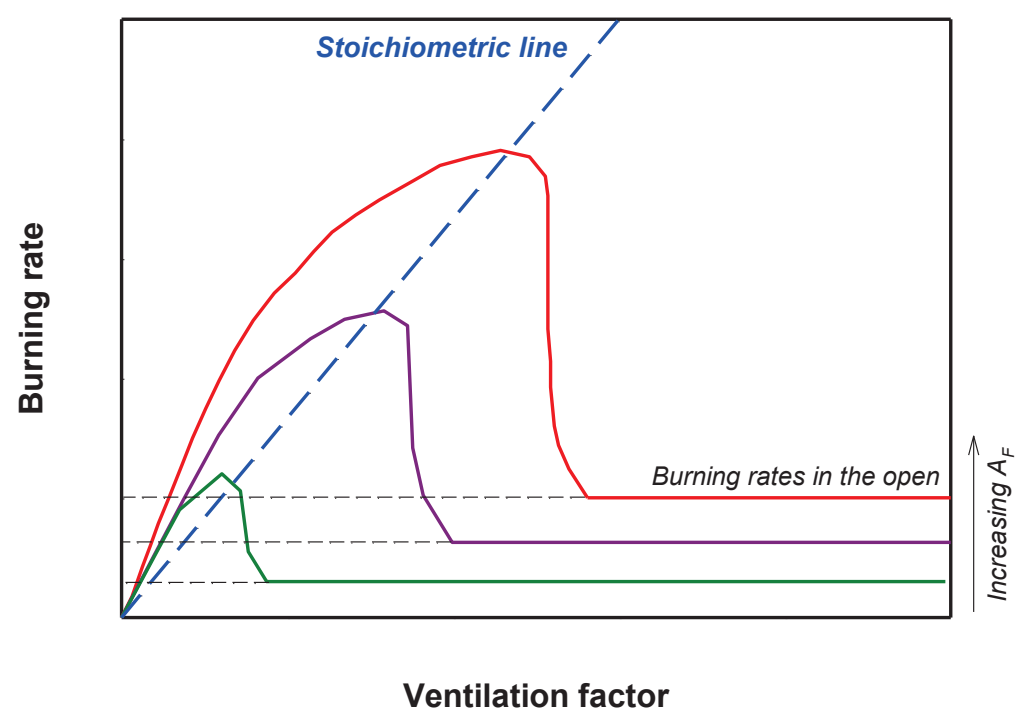

Figure 1. Schematic diagram showing the variation of mass burning rate with ventilation factor and fuel bed area. The three solid lines represent three different fuel areas, $A_{F}$. Adapted from [1].

The non-linear dynamics, flashover and instabilities occurring in compartment fires were later examined in [3], where a simplified model of fire growth was developed and a preliminary analysis of the dynamics was conducted. Similarly to 
the behaviour depicted in [2], a sudden drop was predicted. Although consistent with the predictions, the small number of reduced-scale experiments presented in [4] makes the comparison rather limited. A more detailed and comprehensive model for a fully-developed fire has been developed in [7], based on a well-stirred reactor approach (i.e., the gas is assumed to have uniform properties throughout the compartment). A set of three conservation equations for mass, oxygen and energy is solved in conjunction with sub-models for (i) fuel response (to feedback enhancement and vitiated oxygen effects), (ii) near-vent mixing, (iii) vent flows, and (iv) flame extinction. The model in [7] has been reported to show good agreement with reduced-scale experiments.

In [13], the burning rate in mechanically-ventilated fires has been investigated in a similar way to natural ventilation conditions by controlling the mechanical ventilation flow rates (which is analogous to the ventilation factor in natural ventilation cases). The rate of ventilation can be also expressed as a renewal rate (named here TR), calculated as the volumetric mechanical flow rate divided by the volume of the room (a closed vessel in this case). The burning rates of HTP (Hydrogenated Tetrapropylene) pool fires in a $120 \mathrm{~m}^{3}$ room with renewal rates ranging from 1.5 to $8.4 \mathrm{~h}^{-1}$ have been reported in [13]. Two values for the fuel area, $A_{F}$, were investigated: $0.2 \mathrm{~m}^{2}$ and $0.4 \mathrm{~m}^{2}$. The measured burning rates in free atmosphere conditions vary between 25.7 and $28.8 \mathrm{~g} . \mathrm{s}^{-1} \cdot \mathrm{m}^{-2}$. For most of the compartment tests (i.e. PRS-SI-D1, PRS-SI-D2, PRS-SI-D5, and PRS-SI-D5a) the burning rate reaches a ventilation-controlled steady-state value (indicated in Table 1) before extinction occurs by lack of fuel. Only for test PRS-SI-D3 extinction occurred due to lack of oxygen. Therefore, steady-state conditions were not reached. The value of $8 \mathrm{~g} / \mathrm{s}$ indicated between brackets for PRS-SI-D3 in Table 1 is rather an average MLR (Mass Loss Rate) during the burning period.

An analysis of the experimental data provided in [13] has been performed in [14] by applying the well-stirred reactor approach developed in [7] in quasi-steady state conditions. The analysis relied on the assumption that "the room temperatures do not cause significant additional heat flux to the fuel surface and therefore additional pyrolysis". This assumption remained valid for the range of fire sizes examined in [13]. 
Table 1. Test data for the burning rates of HTP in [13].

\begin{tabular}{|c|c|c|c|c|c|c|}
\hline & Test name & $A_{F}\left(\mathrm{~m}^{2}\right)$ & $\dot{V}\left(\mathrm{~m}^{3} / \mathrm{s}\right)$ & $\begin{array}{l}\text { TR } \quad(h \\
1)\end{array}$ & $\dot{m}_{\mathbf{q}}(\mathrm{g} / \mathrm{s})$ & $\dot{\mathbf{m}}_{\mathbf{a}}\left(\mathrm{g} / \mathrm{m}^{2} . \mathrm{s}\right)$ \\
\hline \multirow{4}{*}{$\begin{array}{l}\text { Free } \\
\text { atmosphere }\end{array}$} & PRS-SI-S1 & 0.2 & - & - & 5.6 & 28.1 \\
\hline & PRS-SI-S2 & 0.2 & - & - & 5.1 & 25.7 \\
\hline & PRS-SI-S3 & 0.4 & - & - & 11.5 & 28.8 \\
\hline & PRS-SI-S4 & 0.4 & - & - & 11.2 & 27.9 \\
\hline \multirow[t]{5}{*}{ Compartment } & PRS-SI-D1 & 0.4 & 0.155 & 4.7 & 4.1 & 10.3 \\
\hline & PRS-SI-D2 & 0.4 & 0.277 & 8.4 & 6.1 & 15.2 \\
\hline & PRS-SI-D3 & 0.4 & 0.049 & 1.5 & $(8.0)$ & $(20.0)$ \\
\hline & PRS-SI-D5 & 0.2 & 0.151 & 4.6 & 2.8 & 14.0 \\
\hline & PRS-SI-D5a & 0.2 & 0.053 & 1.6 & 2.3 & 11.4 \\
\hline
\end{tabular}

In the work presented in the present paper, we (i) apply the well-stirred reactor analysis [7] to a wider range of experimental conditions (i.e., fuel area and ventilation flow rates) in a confined and mechanically-ventilated single-room fire, and (ii) compare the outcome to the research findings discussed above for naturally ventilated enclosure fires. Although the limitations of the well-stirred reactor assumption have been carefully reviewed and examined (mainly from a structural analysis standpoint) in [19], it is believed here to provide useful additional insight into the fire dynamics. More specifically, the main motivation of the work is to provide guidance in the selection of 'design' fires when performing a Fire Hazard Analysis (FHA) for nuclear facilities. In "design" calculations for a FHA, the most common and simple approach consists of prescribing the heat release rate (HRR) curve of a fire in a CFD or a zone model code in order to have an evaluation of the subsequent thermal conditions. The HRR curve is estimated from experimental measurements in open atmosphere conditions for several combustibles. In nuclear facilities, these items could be, e.g., liquid fuel pools (such as HTP used for reprocessing), cable trays or electrical cabinets. Contrarily to the vitiation effect and the ventilation conditions, which are often taken into consideration, the thermal feedback effect and the subsequent enhanced burning rates are not systematically accounted for. As a result, "worst" case scenarios (where the HRR is significantly higher than in open-atmosphere conditions) might be overlooked. The proposed simple wellmixed reactor approach in conjunction with a fuel response model can be used (as 
shown in the section "Influence of ventilation and fuel area") as a preliminary screening tool to evaluate the maximum burning rate that can occur in the case of fire in a well-confined and a mechanically-ventilated room, given the room dimensions and the normal operating ventilation conditions. The maximum burning rate value can then be fed into a more sophisticated code, such as a CFD code, in order to examine in more detail the fire dynamics without having to model air vitiation, pyrolysis, and/or the heat feedback to the fuel surface.

The remainder of the paper is as follows. First, the model is described. Then, a validation is proposed based on the experimental data presented in Table 1. Next, the influence of high ventilation conditions and the fuel area is discussed for a wider range before addressing the main outcomes, limitations and future research needs in the 'conclusions' section.

\section{Numerical modelling}

\subsection{Well-stirred reactor model}

\subsubsection{Conservation equation for mass}

The well-stirred reactor model is based on the solution of three conservation equations for mass, oxygen and energy.

The conservation equation for mass is expressed as:

$$
V \frac{d \rho}{d t}=\dot{m}_{F}+\dot{m}_{i n}-\dot{m}_{e x}
$$

where $V$ is the volume of the room, $\rho$ is the gas density, $t$ is time, $r \dot{\mathbf{m}}_{\mathbf{m}}$ is the fuel mass loss rate, and $\dot{n_{\mathbf{m}}}$ and $\dot{\dot{m}_{\mathbf{m}}}$ are respectively the inlet and exhaust mass flow rates.

The fuel mass flow rate is expressed as:

$$
\dot{m}_{F}=\dot{m}_{F}^{\prime} A_{F}
$$

where 
The inlet and exhaust mass flow rates are expressed as:

$$
\dot{m}_{i n}=\boldsymbol{\Xi}_{i n} \dot{\boldsymbol{L}} \text { and } \dot{m}_{e x}=\boldsymbol{\Omega}_{e x} \dot{\boldsymbol{L}}
$$

where $\dot{V}_{\text {ma }}$ and $\dot{V}_{\text {. }}$ are the volume flow rates at respectively the inlet and exhaust ducts. For most calculations, the inlet gas density is taken as the ambient air density, $\rho_{a}$, and the exhaust gas density is taken as the gas density within the room (i.e. $\rho_{i n}=\rho_{a}$ and $\rho_{e x}=\rho$ ). However, the pressure increase during the course of the fire may cause the inlet fan to reach its stall pressure (more details are provided in the section on mechanical ventilation). A further increase in pressure results in a reverse flow where the inlet fan acts as an exhaust. In this situation, the inlet density becomes equal to the gas density as for an exhaust fan (i.e. $\rho_{\text {in }}=\rho$ ). At extinction, a substantial underpressure may cause the exhaust fan to reach its stall pressure, making it act as an inlet fan. The density at the exhaust then becomes the ambient density (i.e. $\rho_{e x}=\rho_{a}$ ). In reality, the transition may not be as instantaneous as described in the model, especially in the presence of a complex ductwork for ventilation. However, it is believed that this will not have a significant influence on the end results for the steady-state stage. The gas temperature is computed from the density using the ideal gas equation:

$$
T=\frac{\rho_{a} T_{a}}{\rho}=\frac{353}{\rho}
$$

where $T_{a}$ is the ambient temperature.

\subsubsection{Oxygen concentration conservation}

The conservation equation for oxygen is expressed as:

$$
V \frac{d\left(\rho Y_{O_{2}}\right)}{d t}=\dot{m}_{i n} Y_{O_{2}, i n}-\dot{m}_{e x} Y_{O_{2 \boldsymbol{e x}} e x}-\frac{\dot{Q}_{\mathbf{m}}}{\mathbf{\Delta} H_{O_{2}}}
$$


where $Y_{\mathrm{O}_{2}}$ is the oxygen mass fraction within the room and $Y_{\mathrm{O}_{2}, \text { in }}$ and $Y_{\mathrm{O}_{2}, \text { ex }}$ are the oxygen mass fractions at respectively the inlet and exhaust ducts. The variables $\dot{Q}_{\text {n }}$ and $\Delta H_{O_{2}}$ denote respectively the heat release rate from the fire and the heat of combustion per unit mass of oxygen consumed. For most calculations these mass fractions are expressed as $Y_{\mathrm{O}_{2}, \text { in }}=Y_{\mathrm{O}_{2} \text {,open }}$ and $Y_{\mathrm{O}_{2}, \text { ex }}=Y_{\mathrm{O}_{2}}$ (where $Y_{\mathrm{O}_{2} \text {,open }}$ is the oxygen mass fraction in open ambient conditions). However, when the inlet fan acts as an exhaust (as explained earlier), one obtains $Y_{\mathrm{O}_{2}, \text { in }}=Y_{\mathrm{O}_{2}}$. Similarly, if the exhaust fan acts as inlet, the oxygen mass fraction is expressed as $Y_{\mathrm{O}_{2}, \text { ex }}=Y_{\mathrm{O}_{2} \text {,open }}$. This modeled sudden transition is believed not to alter the results significantly as underlined for the density in the previous sub-section.

\subsubsection{Energy conservation}

The conservation equation for energy is expressed as:

$$
\frac{V}{\gamma-1} \frac{d P}{d t}=c_{p} \dot{m}_{i n} T_{i n}-c_{p} \dot{m}_{e x} T_{e x}+c_{p} \dot{m}_{F} T_{v}+\dot{Q}_{f}-\dot{Q}_{\mathbf{m}}
$$

where $\gamma$ is the isentropic coefficient of the gas, $P$ is the pressure inside the room, $c_{p}$ is the specific heat of gases, $T_{i n}$ and $T_{e x}$ are the temperatures at the inlet and exhaust ducts calculated from the densities, $T_{v}$ is the vaporization temperature of the liquid, and $\dot{Q}_{\mathbf{m}}$ is the heat loss to the boundaries.

The heat loss to the boundaries is expressed as a series of natural convection (from the gas to walls, ceiling and floor) and conduction (through the solid boundaries):

$$
\dot{Q}_{w}=\left(h_{c}^{-1} h_{k}^{-1}\right)^{-1} A_{w}\left(T-T_{a}\right)
$$

where $h_{c}$ is the convective heat transfer coefficient from natural convection (taken as constant, see Table 2), $h_{k}$ is the conductive heat transfer coefficient, and $A_{w}$ is the surface area of the boundaries. For the conductive heat transfer coefficient, it is assumed that the solid boundaries are 'thermally thick' [18]: 


$$
h_{k}=\left(\frac{k_{w} \rho_{w} c_{p, w}}{t}\right)^{1 / 2}
$$

where $k_{w}, \rho_{w}$ and $c_{p, w}$ are respectively the conductivity, density and heat capacity of the boundaries, and $t$ is time.

The 'thermally thick' assumption is likely to be true for a compartment in nuclear power plants. However, it might not be applicable for other cases.

\subsection{Fuel response and mechanical ventilation sub-models}

\subsubsection{Fuel mass loss rate}

The fuel mass loss rate per unit area (MLRPUA) is expressed as:

$$
\dot{m}_{F}^{\prime \prime}=\dot{m}_{F, \text { open }}^{\prime \prime}\left(2.1 \frac{Y_{O_{2}}}{Y_{O_{2}, \text { open }}}-1.1\right)+\frac{\dot{q}_{\mathbf{m}}^{\prime}}{L_{v}}
$$

where $\dot{\mathbf{m}}_{r, \text { open }}^{\prime}$ is the fuel mass loss rate per unit area (MLRPUA) in free-burn conditions, $\dot{q}^{\prime}$ is the net radiative heat flux at the fuel surface (assuming an absorptivity equal to unity) and $L_{v}$ is the heat of vaporization of the liquid.

The first term on the right hand side in Eq. (9) expresses the oxygen effect on the fuel mass loss rate (i.e. linear decrease) in vitiated conditions as proposed in [5]. The physical explanation proposed in [20] is the following. As the oxygen content in the vicinity of the fire decreases, the flame becomes less sooty, inducing less radiative feedback at the surface of the pool and subsequently a decreasing pyrolysis rate. The second term on the right hand side in Eq. (9) expresses the effect of thermal radiative feedback on the vaporization of the liquid as proposed in [7].

The MLRPUA in free-burn conditions, $\dot{\mathbf{m}}_{H, \text { open }}^{\prime}$, is expressed according to [21] as:

$$
\dot{m}_{F, \text { open }}^{\prime \prime}=\dot{m}_{F \mathbf{n}}^{\prime \prime}\left(\mathbf{1}-e^{-K D}\right)
$$


where is the limiting MLRPUA, $K$ is an extinction coefficient and $D$ is the diameter of the fire.

The external radiative heat flux, $\dot{q}^{\prime}$, is expressed as:

$$
\dot{q}_{R}^{\prime \prime}=F \sigma \varepsilon\left(T^{4}-T_{v}^{4}\right)
$$

where $F$ is the configuration factor (taken here as 1), $\sigma$ is the Stefan-Boltzmann constant and $\varepsilon$ is the gas emissivity.

\subsubsection{Burning rate and heat release rate}

In order to calculate the burning rate, the amount of mass of oxygen within the enclosure is tracked. If enough oxygen is available in the room to have all the vaporized fuel burning (i.e. fuel-controlled fire), the burning rate is calculated as:

$$
\dot{m}_{b}=\dot{m}_{F}^{\prime} A_{F}
$$

When the fire becomes ventilation-controlled (i.e., depends on the amount of oxygen supplied by the mechanical ventilation system), the burning rate is calculated as:

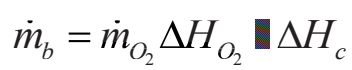

where $\dot{\mathbf{m}}_{\mathbf{n}}$ is the mass flow rate of oxygen within the enclosure.

The heat release rate of the fire is then expressed as:

$$
\dot{Q}_{f}=\dot{m}_{b} \mathbf{\Delta} H_{c}
$$

where $\chi$ is the combustion efficiency and $\Delta H_{c}$ is the heat of combustion of the fuel. 


\subsubsection{Mechanical ventilation}

The volume flow rates at the inlet and exhaust ducts $\dot{V}_{\mathbf{m}}$ and $\dot{V}_{\mathbf{m}}$ are modeled to follow quadratic curves and are expressed as:

$$
\begin{aligned}
& \left.\dot{V}_{i n}=\dot{V}_{0, i n} \operatorname{sign} \backslash \Delta p_{\text {max }, \text { in }}-\Delta p\right) \sqrt{\frac{\left|\Delta p-\Delta p_{\text {max }, i n}\right|}{\Delta p_{\text {max }, i n}}} \\
& \left.\dot{V}_{e x}=\dot{V}_{0, e x} \operatorname{sign} \backslash \Delta p_{\text {max }, e x}-\Delta p\right) \sqrt{\frac{\left|\Delta p-\Delta p_{\text {max }, e x}\right|}{\Delta p_{\text {max }, e x}}}
\end{aligned}
$$

where $\dot{V}_{\text {man }}$ and $\dot{V}_{\text {me }}$ are the volume flow rates at the initial (i.e. ambient) conditions, $\Delta p_{\text {max }, i n}$ and $\Delta p_{\text {max, ex }}$ are the stall pressures of the fans placed at the inlet and exhaust ducts and $\Delta p$ is the pressure difference between the inside and the outside (i.e., at ambient conditions).

\subsection{Algorithmic structure of the code}

Figure 2 shows the algorithmic structure of the code. As mentioned above, the calculation procedure is based on the solution of three conservation equations for mass, oxygen concentration and energy and four sub-models (i.e. ventilation flow rates, fuel response model, burning rate and heat losses to walls). The connection between the sub-models and the conservation equations is clearly indicated in Figure 2 (with the arrows on the side). The calculation sequence (in chronological order) is indicated by a number preceding each step (i.e. solution of a sub-model or a conservation equation). The oxygen concentration and the burning rate are solved simultaneously by first considering both fuel-controlled and ventilationcontrolled conditions and then selecting the appropriate one as explained above. The simulation time for all the calculations presented here is 1 hour. 


\section{Calculation procedure}

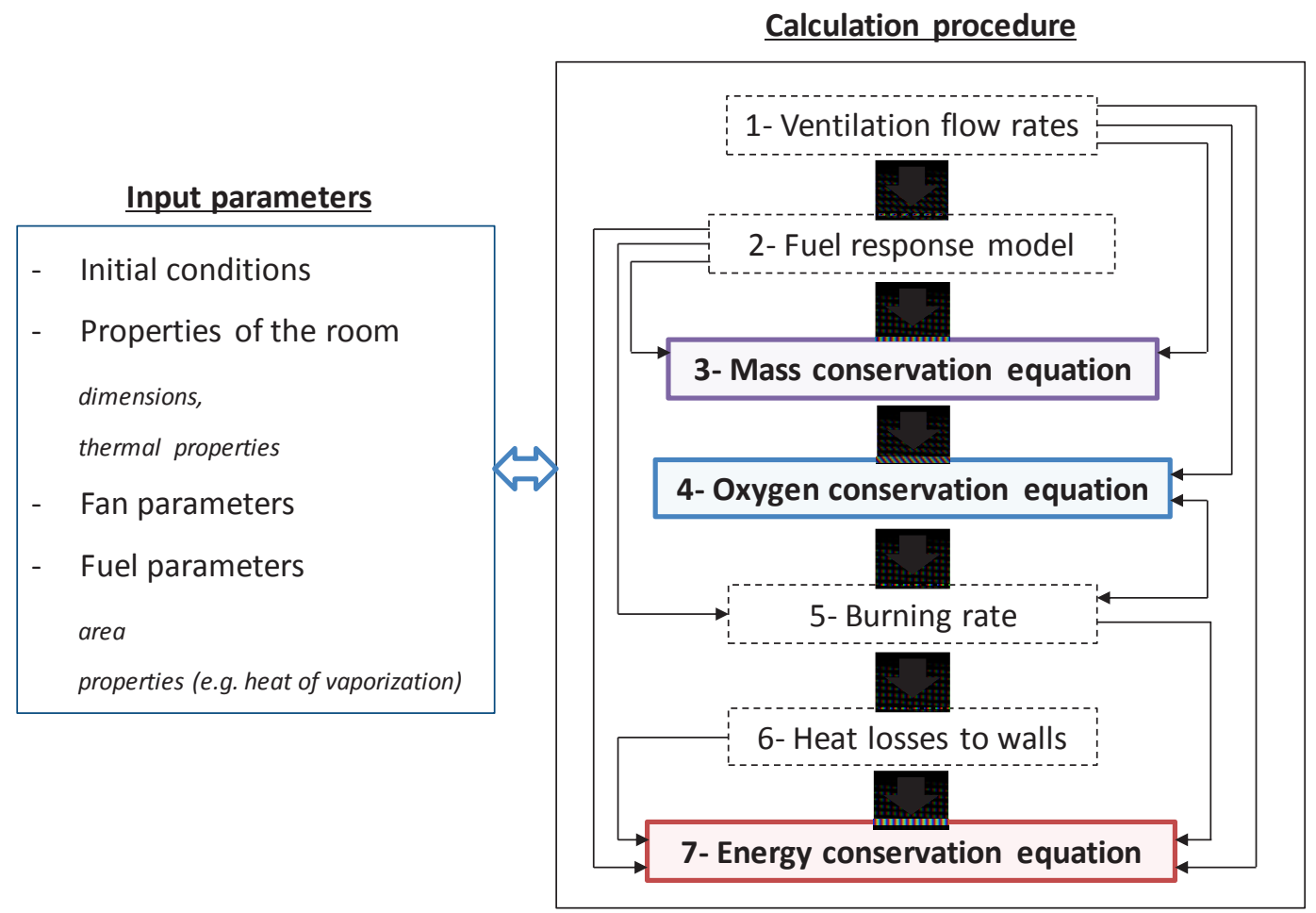

Figure 2. Flow chart of the algorithmic structure of the code.

\section{Validation for low ventilation flow rates}

The validation proposed in this section is based on the experimental data presented in Table 1 [13].

Before addressing the compartment fires, the limiting burning rate and extinction coefficient in Eq. (10) have been calibrated against the mass loss rate values for free atmosphere conditions displayed in Table 1. The obtained values used throughout the calculations presented in the present paper are 任, $-0.070 \mathrm{~kg} / \mathrm{m}^{3} . \mathrm{s}$ and $K=2 \mathrm{~m}^{-1}$. Furthermore, a period of $100 \mathrm{~s}$ is prescribed in the model for the MLR (Mass Loss Rate) to reach steady-state. The extinction by lack of fuel is not taken into account in this study. The purpose is to focus on ventilation-controlled steady-state burning rates. Figure 3 shows a comparison between the measured and modeled transient MLR profile in free atmosphere conditions. 

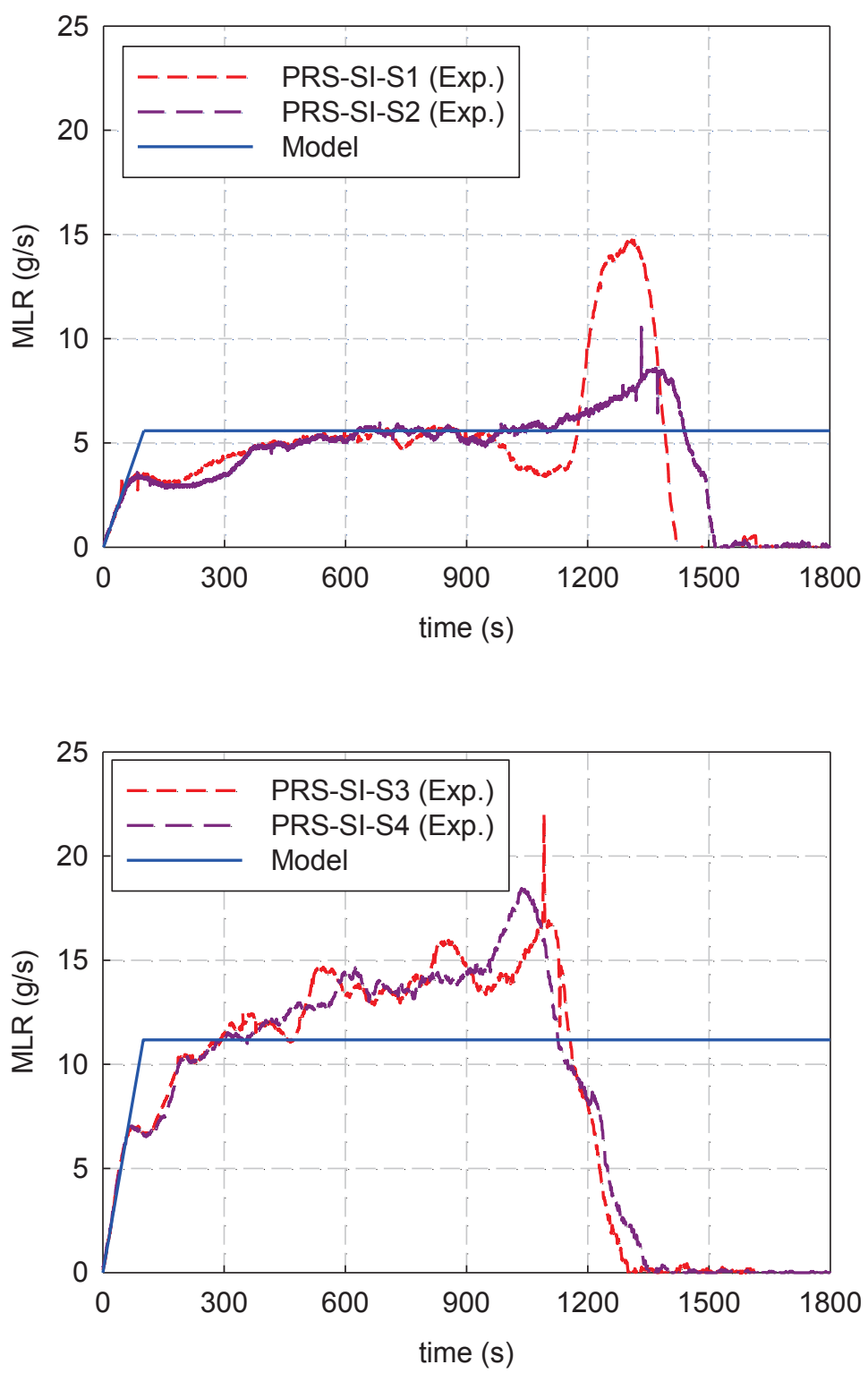

Figure 3. Comparison between the measured and modeled transient Mass Loss Rates (MLR) profiles in free atmosphere conditions.

\subsection{Configuration}

The geometrical configuration considered in this work is shown in Fig. 4. It consists of a well-confined and mechanically-ventilated room. The ventilation system consists of an inlet fan and an exhaust fan that releases smoke to the atmosphere (ambient conditions). A pool fire is placed at floor level. 


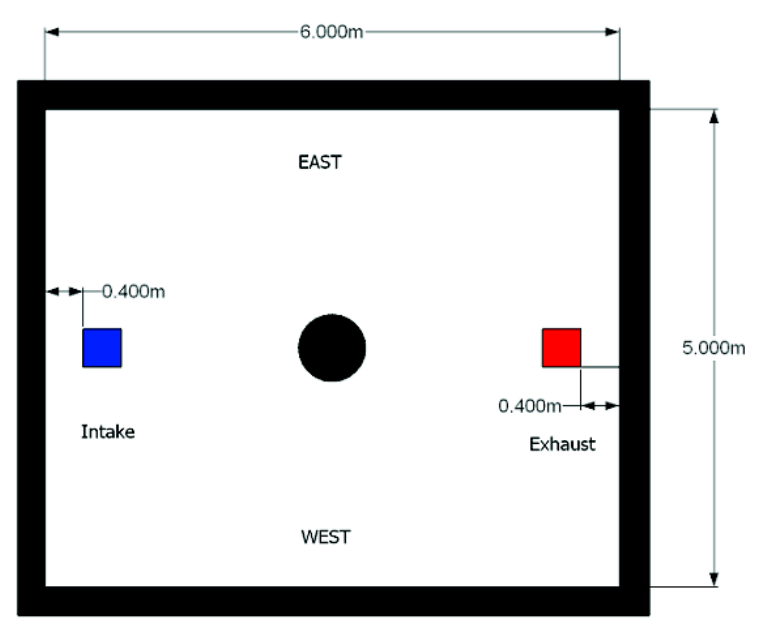

(a)Top view of the fire room

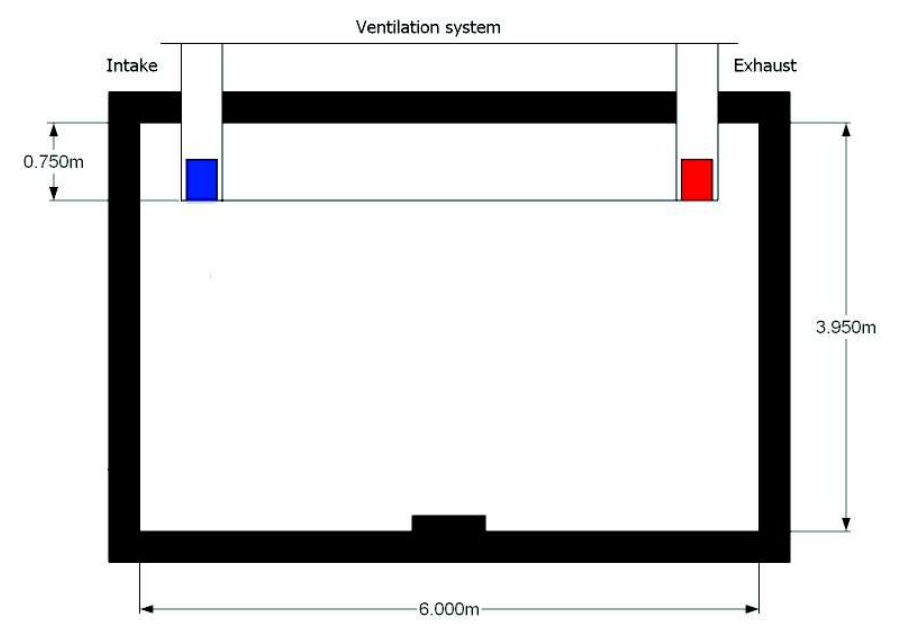

(b) Side view of the fire room

Figure 3. Experimental set-up used in [13-14].

The stall pressures of the fans ( $\Delta p_{\max }$ in Eqs. (15)) were not provided in [13-14]. Values between $250 \mathrm{~Pa}$ and $800 \mathrm{~Pa}$ have been prescribed in the simulations, revealing that there is no significant impact the steady-state heat release rate values.

Table 2 provides the list of remaining parameters as used in the model. 
Table 2. Specified parameters for the model.

\begin{tabular}{|l|l|}
\hline Compartment parameters & \\
\hline$V=120 \mathrm{~m}^{3}$ & Room volume \\
\hline$A=150 \mathrm{~m}^{2}$ & Room surface area \\
\hline Fuel parameters & \\
\hline$L_{v}=361 \mathrm{~kJ} / \mathrm{kg}$ & Heat of vaporization [15] \\
\hline$\Delta H_{c}=42000 \mathrm{~kJ} / \mathrm{kg}$ & Heat of combustion [15] \\
\hline$T_{v}=461 \mathrm{~K}\left(188^{\circ} \mathrm{C}\right)$ & Temperature of vaporization [16] \\
\hline$\Delta H_{O_{2}}=13100 \mathrm{~kJ} / \mathrm{kg}$ & Heat of combustion per unit mass of oxygen \\
\hline Fluid parameters & \\
\hline$\rho_{a}=1.154 \mathrm{~kg} / \mathrm{m}^{3}$ & Ambient air density \\
\hline$T_{a}=306 \mathrm{~K}$ & Ambient air temperature \\
\hline$c_{p}=1 \mathrm{~kJ} / \mathrm{kg} \cdot \mathrm{K}$ & Specific heat of air \\
\hline Heat transfer parameters & \\
\hline$h_{c}=10 \mathrm{~W} / \mathrm{m}^{2} . \mathrm{K}$ & Convective heat transfer coefficient \\
\hline$k_{w}=1.5 \mathrm{~W} /(\mathrm{m} . \mathrm{K})$ & Conductivity of concrete [15] \\
\hline$c_{p, w}=736 \mathrm{~J} /(\mathrm{kg} \cdot \mathrm{K})$ & Specific heat of concrete[15] \\
\hline$\rho_{w}=2430\left(\mathrm{~kg} / \mathrm{m}^{3}\right)$ & Density of concrete [15] \\
\hline$\gamma=1.4$ & isentropic coefficient of the gas \\
\hline$\sigma=5.67 \times 10^{-8} \mathrm{~W} / \mathrm{m}^{2} \mathrm{~K}^{4}$ & Stephan-Boltzmann constant \\
\hline$\chi=1$ & Combustion efficiency \\
\hline$\varepsilon=1$ & Layer emissivity \\
\hline & \\
\hline & \\
\hline
\end{tabular}

\subsection{Results}

First, a detailed account of the results for the PRS-SI-D1 test is given. Figure 5 shows that the peak MLR is overestimated in the transient stage. However, good agreement is obtained for the steady-state ventilation-controlled stage. The ventilation flow rates, pressure, oxygen concentration and average gas temperature profiles displayed in Fig. 6 are qualitatively well reproduced. For instance, the model is able to predict 'well' the pressure increase and reverse flow at the inlet during the transient stage. Similarly to the MLR profile, the predicted four quantities shown in Fig. 6 are in good quantitative agreement with the experimental data. 


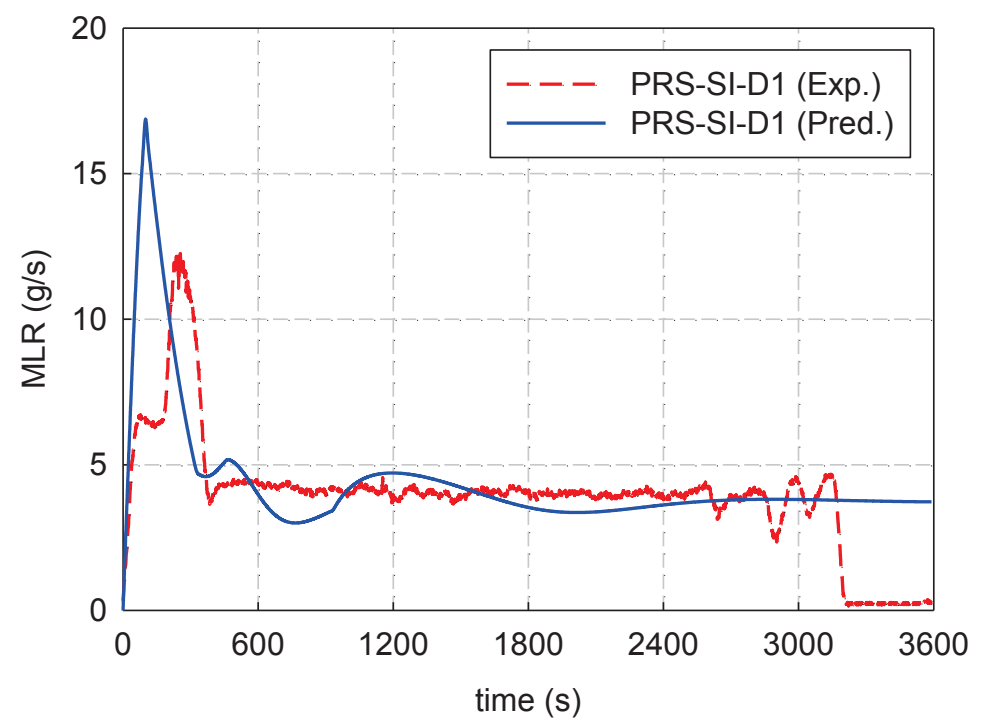

Figure 5. Comparison between the experimental and predicted transient MLR profiles for the PRSSI-D1 test.
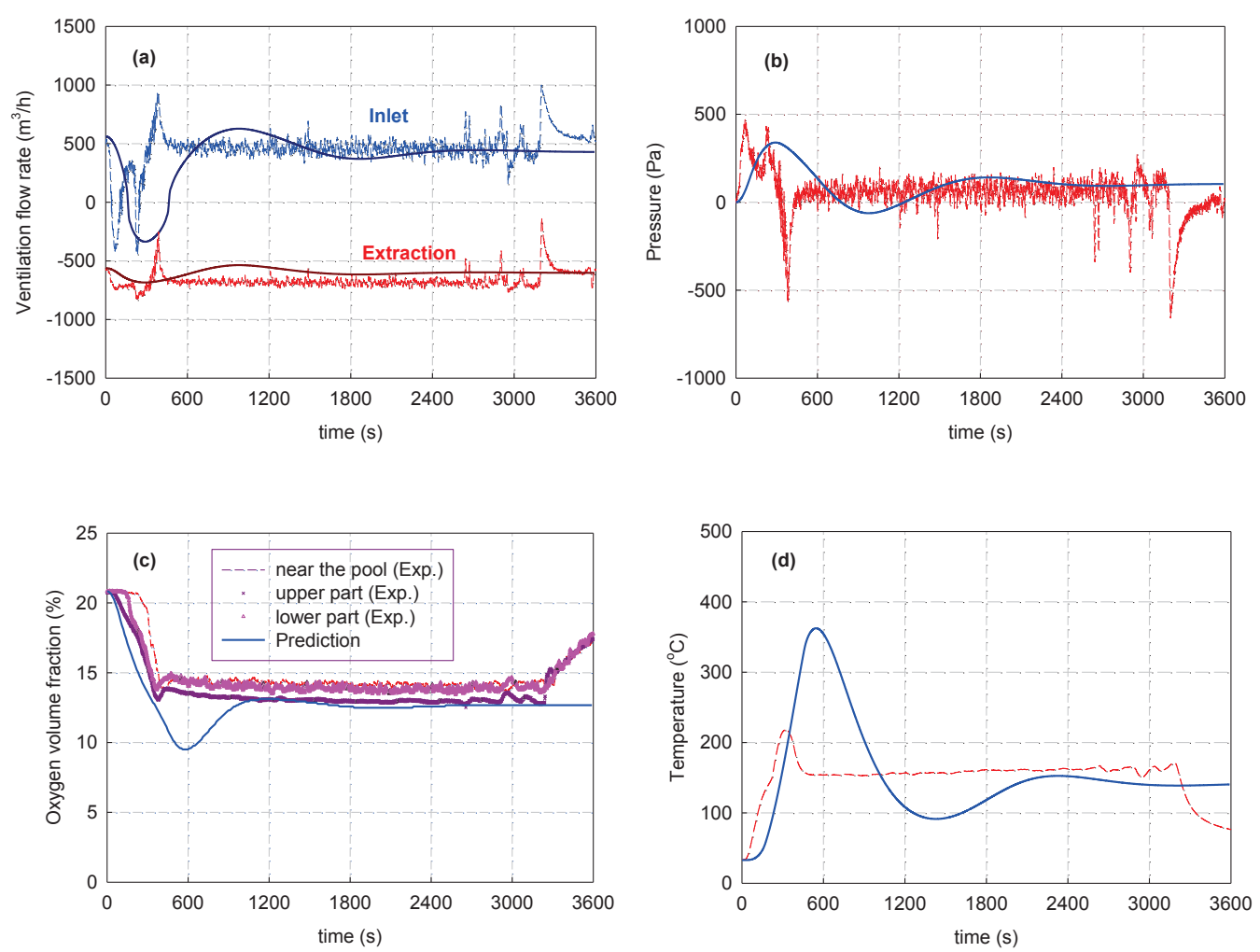

Figure 6. Comparison between the experimental (dashed lines) and predicted (solid lines) transient profiles for the PRS-SI-D1 test. (a) Ventilation flow rates. (b) Pressure. (c) Oxygen concentration. (d) Gas temperature. 
The transient MLR profiles of the other tests, displayed in Fig. 7, also show a good agreement with the experimental data. However, extinction due to lack of oxygen in PRS-SI-D3 was not predicted.
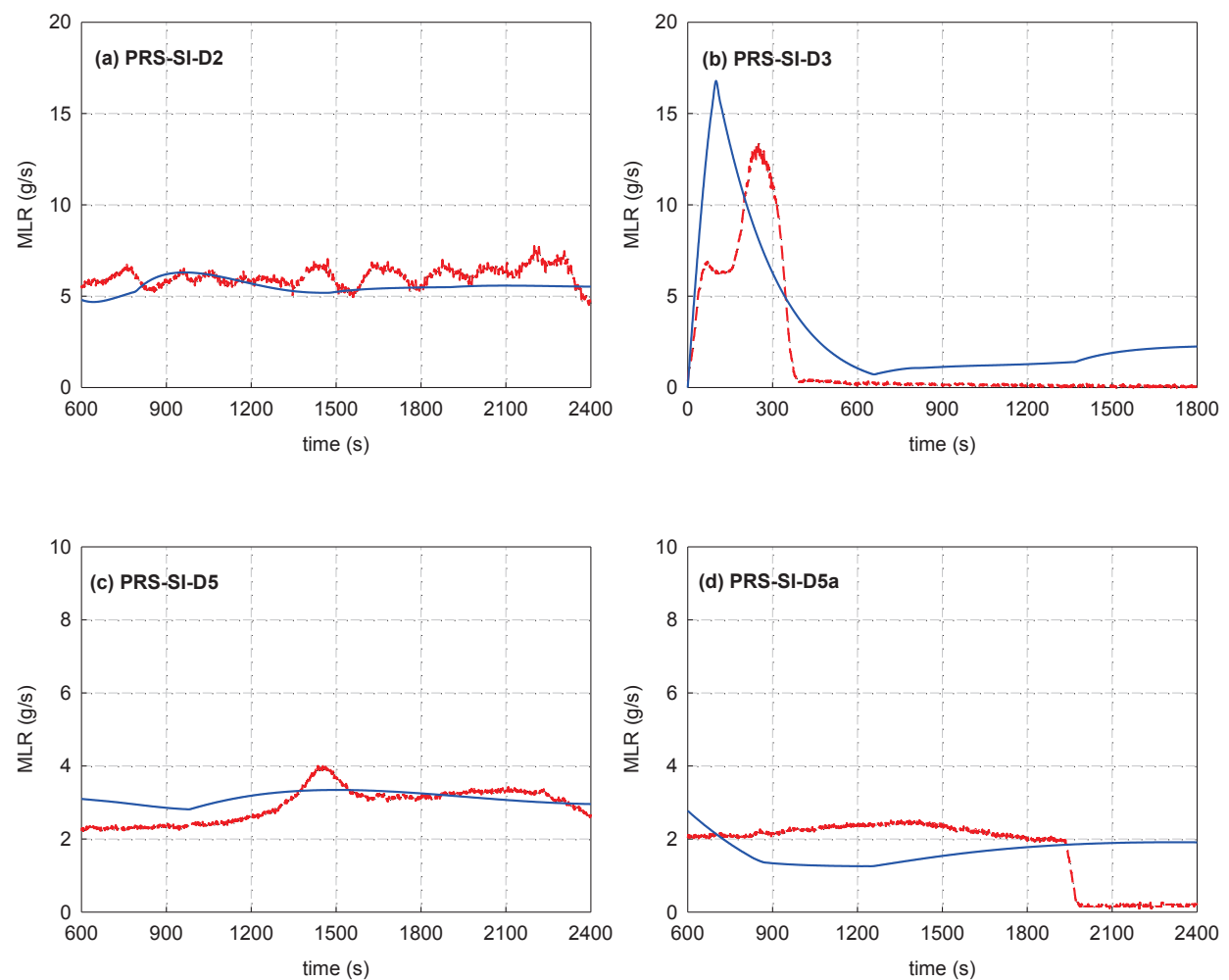

Figure 7. Comparison between the experimental (dashed line) and predicted (solid line) transient MLR profile for (a) PRS-SI-D2, (b) PRS-SI-D3, (c) PRS-SI-D5, (d) PRS-SI-D5a.

The steady-state predictions for the burning rate are shown in Fig. 8 and Table 3. These results show that a relatively good agreement is obtained for all tests (except for PRS-SI-D3 where extinction due to lack of oxygen was not predicted). It is noteworthy that Melis et al. [14] examined additional experimental data (not shown here) where the air inlet was placed at a low position. They concluded that, in such configuration, the available oxygen near the flame base is significantly higher than the mean oxygen concentration, inducing therefore a behaviour more similar to naturally-ventilated fires. Such an effect cannot be predicted with the well-stirred reactor approach as presented here. This is therefore to be considered as a limitation of the present model. 


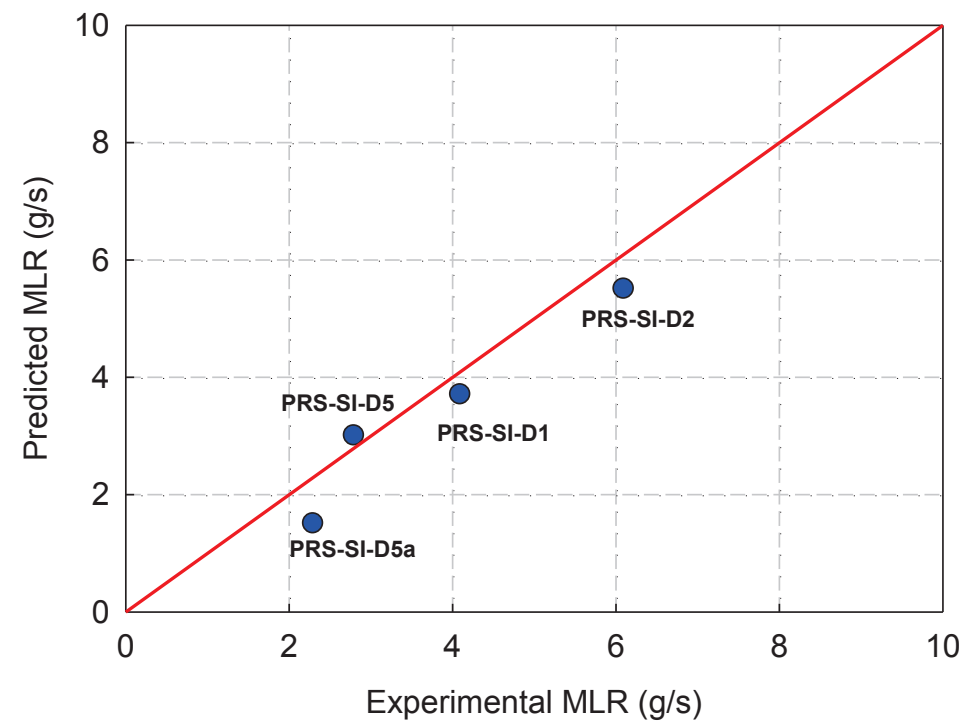

Figure 8. Comparison between the experimental and predicted steady-state MLR for four compartment fires considered in this study.

Table 3. Model predictions and deviations for the steady-state MLR for the 5 compartment fires considered in this study.

\begin{tabular}{|c|c|c|c|c|}
\hline Test name & $\begin{array}{c}\text { Exp. data } \\
(\mathrm{g} / \mathrm{s})\end{array}$ & $\begin{array}{c}\text { Prediction } \\
(\mathrm{g} / \mathrm{s})\end{array}$ & $\begin{array}{c}\text { Relative } \\
\text { deviation }(\%)\end{array}$ & $\begin{array}{c}\text { Absolute } \\
\text { deviation }(\mathrm{g} / \mathrm{s})\end{array}$ \\
\hline PRS-SI-D1 & 4.1 & 3.7 & -10 & -0.4 \\
\hline PRS-SI-D2 & 6.1 & 5.5 & -10 & -0.6 \\
\hline PRS-SI-D3 & - & 1.5 & - & +1.5 \\
\hline PRS-SI-D5 & 2.8 & 3.0 & +7 & +0.2 \\
\hline PRS-SI-D5a & 2.3 & 1.5 & -35 & -0.8 \\
\hline
\end{tabular}

Finally, it is noted that the temperatures measured in [13] remained below $475 \mathrm{~K}$ [14]. Knowing that the vaporization temperature of HTP is $461 \mathrm{~K}$, one can conclude that the thermal feedback effect in [13] is negligible, if not inexistent. Such low temperatures are the result of small fuel areas $\left(0.2\right.$ and $\left.0.4 \mathrm{~m}^{2}\right)$ and limited ventilation flow rates. In the next section the analysis is extended (using the developed single-zone model) to a wider range of fuel areas and ventilation flow rates in order to examine the interaction and influence of these two key elements on the burning rate for more severe conditions. 


\section{Influence of high ventilation flow rates and fuel area}

The sensitivity analysis for the ventilation flow rates and fuel areas proposed in this section is based on the same geometrical configuration [13-14] as displayed in Fig. 3 and using the same parameters of Table 2.

\subsection{Mechanical ventilation effect}

The surface area of the pool fire is taken here as $0.5 \mathrm{~m}^{2}$. The initial ventilation flow rates are varied between 0.1 and $10 \mathrm{~m}^{3} / \mathrm{s}$. In all cases the initial air intake and extraction flow rates are equal. Furthermore, the stall pressures of the fans are taken as $\Delta p_{\max }=1000 \dot{\boldsymbol{M}}$. Such an approach allows covering the full extent of ventilation conditions given by the variation of ventilation flow rates as a function of pressure. Figure 9 shows an example of inlet fan curves considered for initial flow rates between 0.1 and $5 \mathrm{~m}^{3} / \mathrm{s}$.

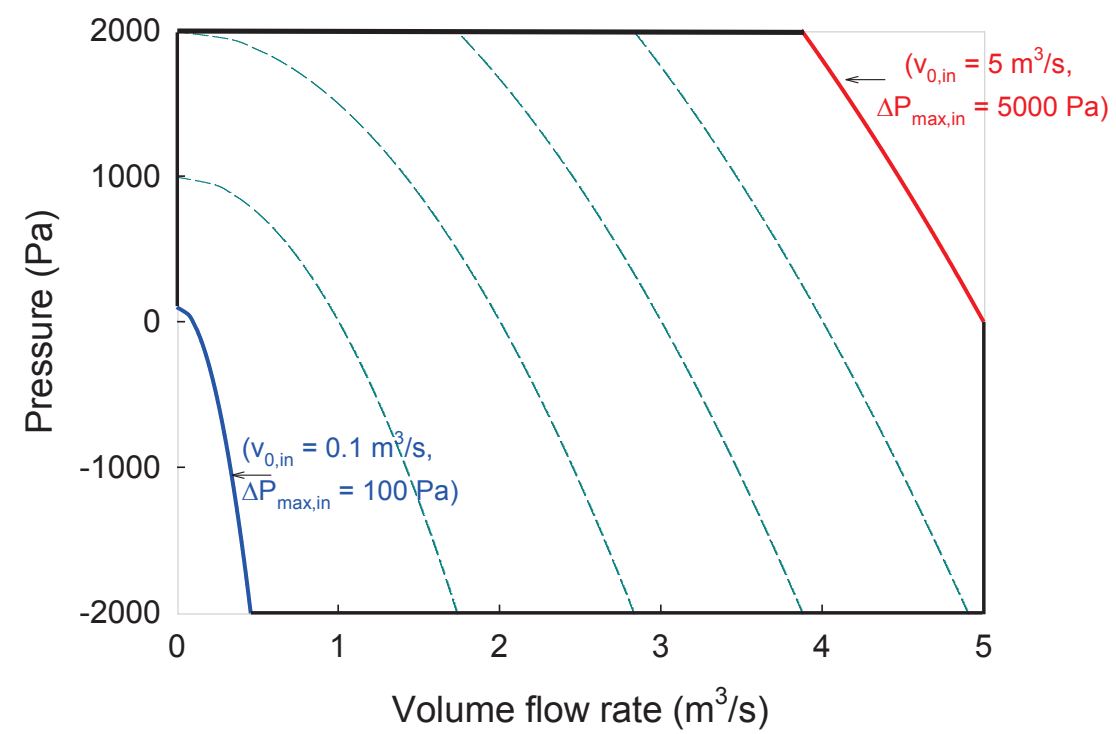

Figure 9. Inlet fan curves considered in the sensitivity study for initial flow rates between 0.1 and $5 \mathrm{~m}^{3} / \mathrm{s}$.

The results of the effect of the ventilation flow rates on the burning rates are displayed in Fig. 10. These results show that when the ventilation flow rates are increased, the burning rates increase to reach, at $2.3 \mathrm{~m}^{3} / \mathrm{s}$, a value that is almost 1.75 times higher than the free-burn one. When increasing the volume flow rate beyond the critical value of $2.3 \mathrm{~m}^{3} / \mathrm{s}$, the heat release rate (HRR) sharply decreases to the free-burn value, similarly to the 'sudden drop' as observed and described for naturally-ventilated enclosure fires [1-2]. 


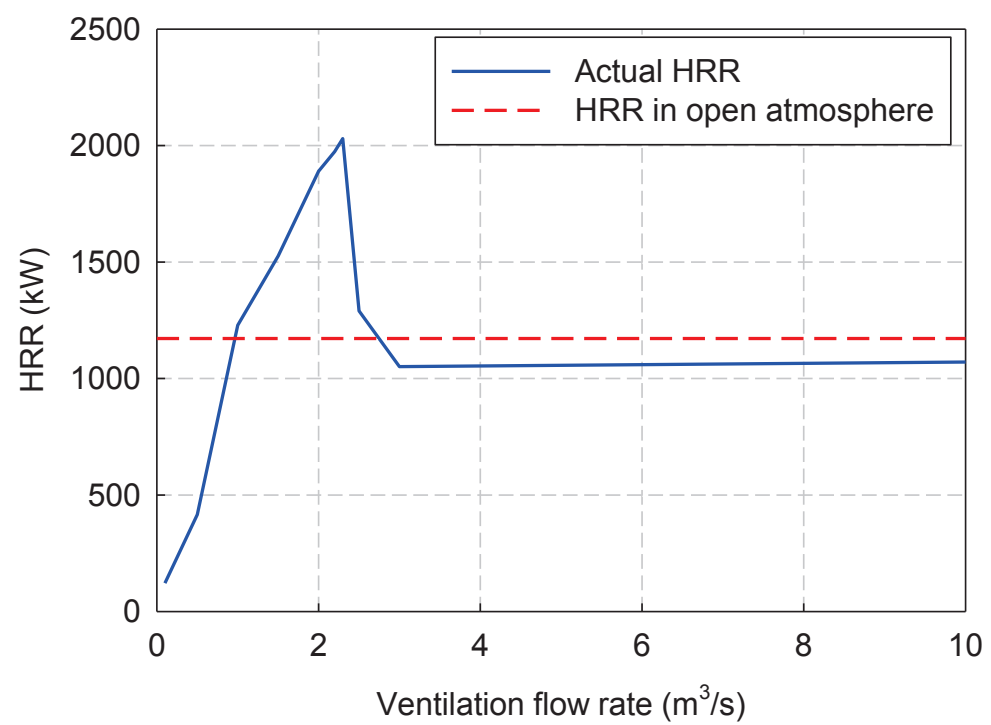

Figure 10. Influence of the mechanical ventilation flow rate on the steady-state HRR for a fuel bed area of $0.5 \mathrm{~m}^{2}$.

Such behaviour is the result of a competition between the enhanced burning due to increased oxygen (allowing higher fuel MLR as result of the thermal feedback), and the mixing effect of hot gases with incoming fresh air which reduces the mean temperature within the enclosure and hence the thermal feedback effect to the fuel surface. In the next sub-section, this behaviour is examined for a wider range of fuel areas.

\subsection{Fuel area effect}

The fuel area has been varied between 0.4 and $1 \mathrm{~m}^{2}$ for ventilation flow rates between 0.1 and $10 \mathrm{~m}^{3} / \mathrm{s}$. The results displayed in Fig. 11 show a clear analogy with the schematic diagram of Fig. 1 for naturally ventilated fires. For fuel areas between 0.5 and $1 \mathrm{~m}^{2}$, the same behaviour as explained in the previous subsection is obtained. For the smaller fuel area of $0.4 \mathrm{~m}^{2}$, there is no peak in the burning rate. The burning behaviour is similar to open atmosphere conditions, because there is no oxygen limitation in this case. For fuel areas beyond $1 \mathrm{~m}^{2}$, a ventilation flow rate higher than $10 \mathrm{~m}^{3} / \mathrm{s}$ was required to depict the sudden drop in the burning rate and the asymptotic behaviour to reach the free-burn value. 


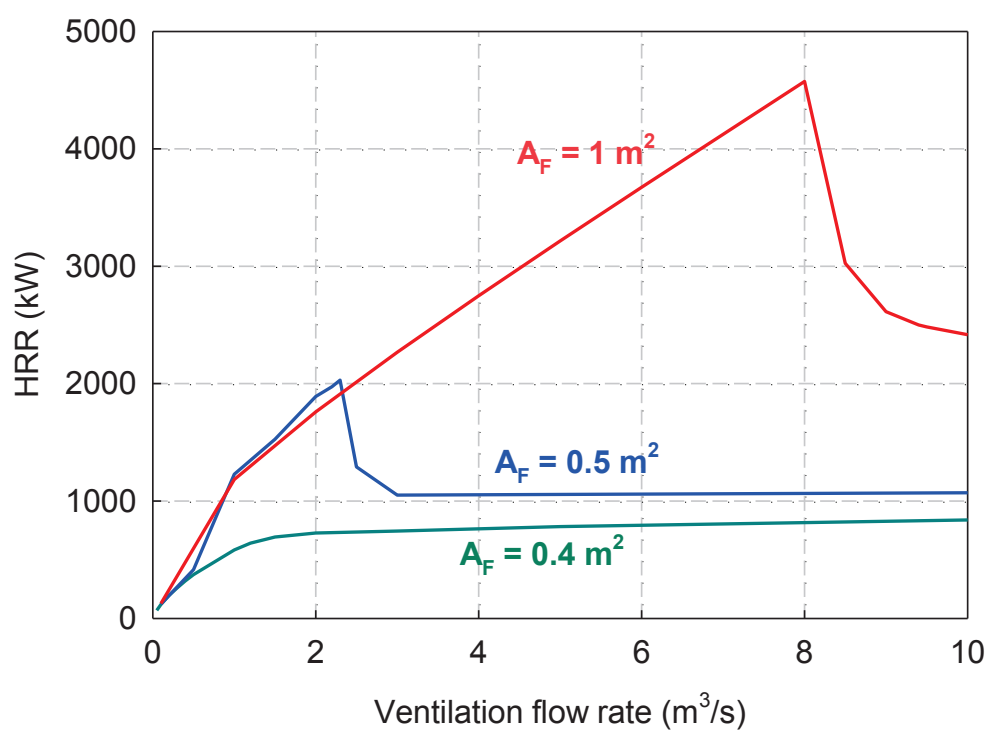

Figure 11. Predicted variation of the steady-state HRR with ventilation flow rates and fuel bed area.

Interestingly, as shown in Fig. 12, the ratio of maximum HRR rate to the open atmosphere HRR (i.e. $\left.H_{R} R_{\max } / H R R \_o p e n\right)$ reaches a maximum constant value around 1.75 for fuel areas higher than $0.4 \mathrm{~m}^{2}$. As suggested in [2] for naturally ventilated fires, this can be explained by an established equilibrium between the rate of fuel gas supply and the rate of air supplied by ventilation.

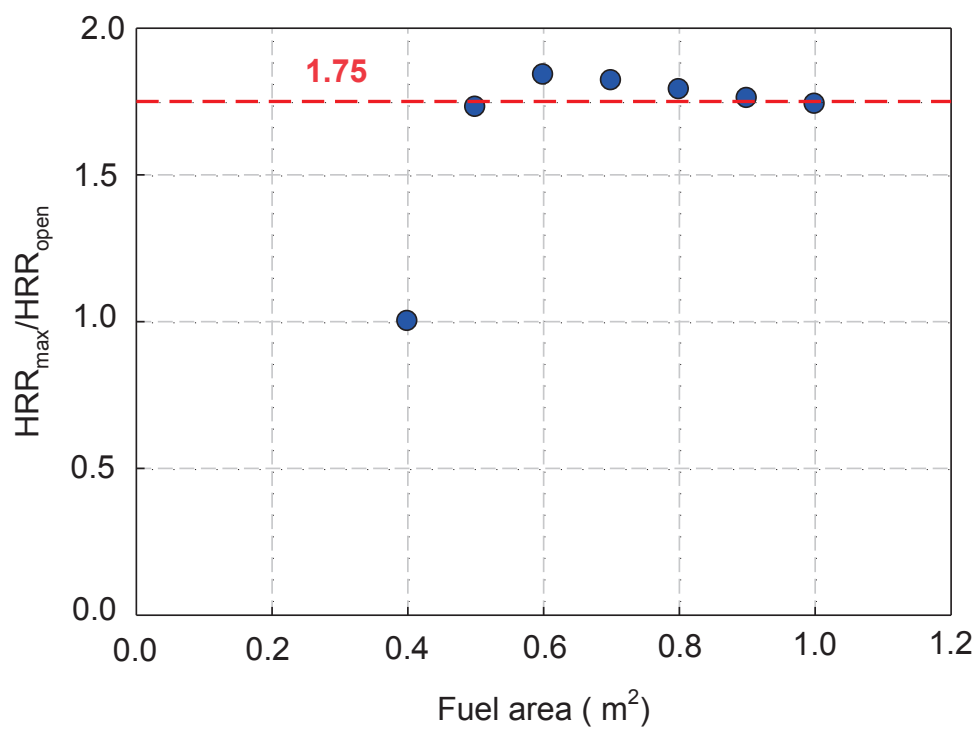

Figure 12. Ratio $\mathrm{HRR}_{\text {max }} / \mathrm{HRR}_{\text {open }}$ as a function of the fuel bed area. 
This is useful information in practice. Indeed, the ventilation flow rates delivered by the fans and the full ventilation network (with the pressure losses between branches and nodes) have maximal (nominal) values. Thus, the maximum steadystate burning rate can be estimated by performing a sensitivity study on the fuel area for the "nominal" ventilation flow rate. Figure 13 shows the results of such a study for two initial ventilation flow rates: 1 and $5 \mathrm{~m}^{3} / \mathrm{s}$. For the $1 \mathrm{~m}^{3} / \mathrm{s}$ curve there is a strong increase in the HRR up to a fuel area of around $0.5 \mathrm{~m}^{2}$. Then, the steady-state HRR decreases very slightly with increased fuel area. The $5 \mathrm{~m}^{3} / \mathrm{s}$ curve shows that the burning rate for fuel areas below $0.7 \mathrm{~m}^{2}$ remains below the free-burn value due to a vitiation effect. However, between $0.7 \mathrm{~m}^{2}$ and $1.2 \mathrm{~m}^{2}$ the thermal feedback effect is stronger than the vitiation effect, yielding burning rates significantly higher than the free-burn values (up to 1.75 times). When the fuel bed area becomes too large (in this case beyond $1.2 \mathrm{~m}^{2}$ ) the burning rate is mainly controlled by the oxygen supply through the ventilation system and drops to a value below the free-burn conditions again.

Summarizing, the present model can be used as screening tool to determine the 'worst case' scenario in terms of HRR as mentioned before.

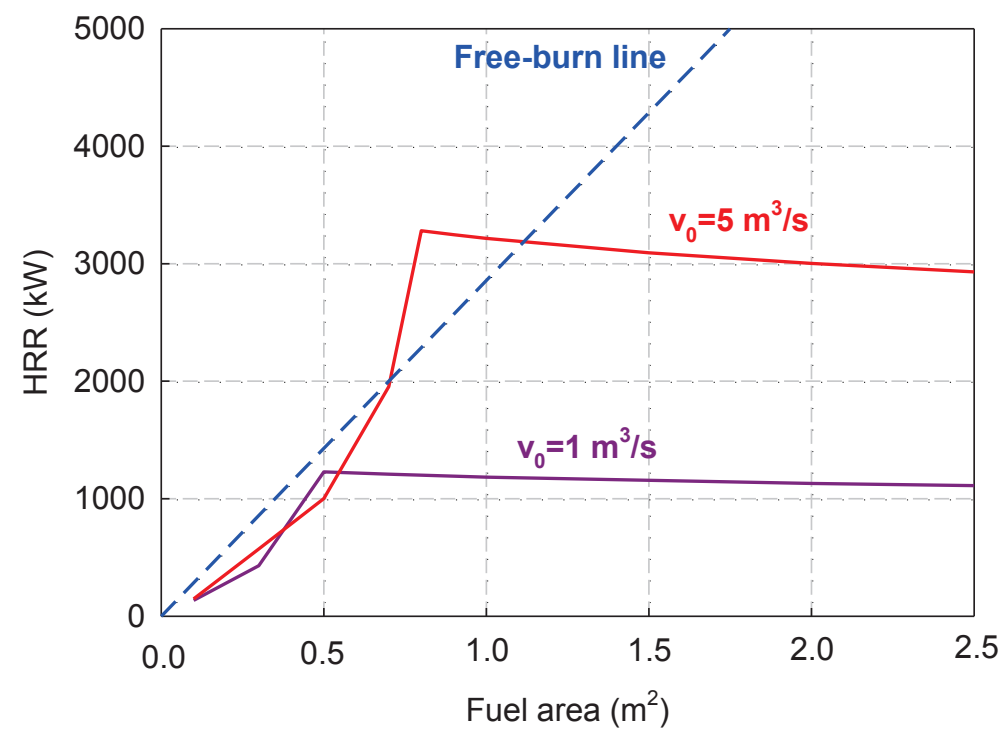

Figure 13. Steady-state HRR as a function of the fuel area for two ventilation flow rates. 


\section{Conclusion}

A single-zone model for fire dynamics in a well confined and mechanicallyventilated room has been developed as a support tool to be considered prior to more detailed and time consuming CFD calculations. The model solves three conservation equations for (i) mass, (ii) oxygen concentration, and (iii) energy, in conjunction with a fuel response model and a quadratic model for the mechanical ventilation. The fuel response model incorporates the limiting oxygen effect and the thermal effect (i.e., radiative feedback to the fuel surface). As output, the model provides the temperature, oxygen concentration and pressure within the room and, most importantly, the burning rate (or HRR).

The model was first evaluated based on experiments for pool fires of 0.2 and 0.4 $\mathrm{m}^{2}$ with limited ventilation conditions. A relatively good agreement with the experimental data was obtained (with deviations within $\pm 10 \%$ for most of the experimental data).

The model results were examined afterwards for a broader set of conditions (in terms of mechanical ventilation and fuel area). The extensive sensitivity study illustrated a balance between the (1) fuel mass loss rate and (2) the supply of air delivered by the fans. Depending on these two parameters and on the properties of the room (i.e. volume, surface area, and thermal boundary conditions) there is a maximum burning rate that cannot be exceeded. This is an important result that can be used to estimate the maximum HRR in design calculations ('worst case' conditions).

The sensitivity study was particularly interesting when the volume flow rates, as delivered by the fans, were varied. It was shown that the steady burning rate increases with increased air volume flow rates up to a critical value, beyond which it drops abruptly and approaches asymptotically the burning rate value in open atmosphere conditions.

\section{References}

[1] Bullen ML, Thomas PH (1979) Compartment Fires with Non-Cellulosic fuels. P Combust Inst. 17:1139-1148. doi.org/10.1016/S0082-0784(79)80108-3

[2] Takeda H, Akita K (1981) Critical Phenomenon in Compartment Fires With Liquid Fuels. P of Combust Inst. 18:519-527. doi.org/10.1016/S0082-0784(81)80057-4 
[3] Bishop SR, Holborn PG, Beard AN, Drysdale DD (1993) Nonlinear dynamics of flashover in compartment fires. Fire Safety J. 21:11-45. doi.org/10.1016/0379-7112(93)90003-9

[4] Holborn PG, Bishop SR, Drysdale DD, Beard AN (1993) Experimental and Theoretical Models of Flashover. Fire Safety J. 21:257-266. doi.org/10.1016/0379-7112(93)90030-T

[5] Peatross MJ, Beyler CL (1997) Ventilation effects on Compartment Fire Characterization. Fire Safety Science- Proceedings of the Fifth International Symposium, pp. 403-414. doi:10.3801/IAFSS.FSS.5-403

[6] Delichatsios MA, Silcock GWH (2003) Fully Involved Enclosure Fires: Effects of Fuel Type, Fuel Area and Geometry. Fire Safety Science- Proceedings of the Seventh International Symposium, pp. 59-73. doi:10.3801/IAFSS.FSS.7-59

[7] Utiskul Y, Quintiere JG, Rangwala AS, Ringwelski BA, Wakatsuki K, Naruse T (2005) Compartment fire phenomena under limited ventilation. Fire Safety J. 40:367-390. doi.org/10.1016/j.firesaf.2005.02.002

[8] Kawagoe K (1958) Fire behaviour in rooms. Report No. 27, Building Research Institute, Tokyo.

[9] Thomas PH, Heselden AJM, Law M (1967). Fully developed compartment fires: two kinds of behaviour. Fire Research Technical Paper No. 18, HMSO, London.

[10] Nishio G, Machida S, (1987) Pool Fires under Atmosphere and Ventilation in Steady-State Burning, Part II. Fire Technol. 23:186-197. doi:10.1007/BF01036935.

[11] McCaffrey BJ, Quintiere JG, Harkleroad MF (1981) Estimating room temperatures and the likelihood of flashover using fire test data correlations. Fire Technol. 17:98-119. doi: 10.1007/BF02479583.

[12] Foote KL, Pagni PJ, Alvares NJ (1985) Temperature correlations for forced-ventilated compartment fires. Fire Safety Science - Proceedings of the First International Symposium, pp.139-148. doi:10.3801/IAFSS.FSS.1-139.

[13] Prétrel H, Querre P, Forestier M (2005) Experimental Study of Burning Rate Behaviour in Confined and Ventilated Fire Compartments. Fire Safety Science - Proceedings of the Eighth International Symposium, pp. 1217-1228. doi:10.3801/IAFSS.FSS.8-1217

[14] Melis S, Audouin L (2008) Effects of Vitiation on the Heat Release Rate in MechanicallyVentilated Compartment Fires. Fire Safety Science - Proceedings of the Ninth International Symposium, pp. 931-942.

doi:10.3801/IAFSS.FSS.9-931

[15] Audouin L et al. (2011) Quantifying differences between computational results and measurements in the case of a large-scale well-confined fire scenario. Nucl Eng Des. 241:18-31. doi.org/10.1016/j.nucengdes.2010.10.027

[16] Bonte F, Noterman N, Merci B (2013) Computer simulations to study interaction between burning rates and pressure variations in confined enclosure fires. Fire Safety J. 26:125-143. doi.org/10.1016/j.firesaf.2013.01.030

[17] Pelzer M, Klein-Heßling W (2013) Validation of COCOSYS pyrolysis models on OECD PRISME fire experiments. Fire Safety J. 62:174-191. doi.org/10.1016/j.firesaf.2013.01.016

[18] Quintiere JG (2006) Fundamentals of Fire Phenomena, Wiley, West Sussex, England. 
[19] Stern-Gottfried J, Rein G, Bisby LA, Torero JL (2010) Experimental review of the homogeneous temperature assumption in post-flashover compartment fires. Fire Safety J. 45:249261. doi.org/10.1016/j.firesaf.2010.03.007

[20] Santo G., Tamanini F (1981) Influence of Oxygen Concentration on the Radiative Properties of PMMA. P Combust Inst. 18:619-631. doi:10.1016/S0082-0784(81)80067-7

[21] Babrauskas V (1983) Estimating large pool fire burning rates. Fire Technol. 19:251-261.

\section{Figures legends}

Figure 1. Schematic diagram showing the variation of mass burning rate with ventilation factor and fuel bed area. The three solid lines represent three different fuel areas, $\mathrm{A}_{\mathrm{F}}$. Adapted from [1]. Figure 2. Flow chart of the algorithmic structure of the code.

Figure 3. Comparison between the measured and modeled transient Mass Loss Rates (MLR) profiles in free atmosphere conditions.

Figure 4. Experimental set-up used in [13-14].

Figure 5. Comparison between the experimental and predicted transient MLR profiles for the PRSSI-D1 test.

Figure 6. Comparison between the experimental (dashed lines) and predicted (solid lines) transient profiles for the PRS-SI-D1 test. (a) Ventilation flow rates. (b) Pressure. (c) Oxygen concentration. (d) Gas temperature.

Figure 7. Comparison between the experimental (dashed line) and predicted (solid line) transient MLR profile for (a) PRS-SI-D2, (b) PRS-SI-D3, (c) PRS-SI-D5, (d) PRS-SI-D5a.

Figure 8. Comparison between the experimental and predicted steady-state MLR for four compartment fires considered in this study.

Figure 9. Inlet fan curves considered in the sensitivity study for initial flow rates between 0.1 and $5 \mathrm{~m}^{3} / \mathrm{s}$.

Figure 10. Influence of the mechanical ventilation flow rate on the steady-state HRR for a fuel bed area of $0.5 \mathrm{~m}^{2}$.

Figure 11. Predicted variation of the steady-state HRR with ventilation flow rates and fuel bed area.

Figure 12. Ratio $H R R_{\max } / H_{R R}$ open as a function of the fuel bed area.

Figure 13. Steady-state HRR as a function of the fuel area for a three ventilation flow rates.

\section{List of tables}

Table 1. Test data for the burning rates of HTP in [13].

Table 2. Specified parameters for the model.

Table 3. Model predictions and deviations for the steady-state MLR for the 5 compartment fires considered in this study. 